\title{
PERSEPSI MASYARAKAT TERHADAP BUAH JERUK LOKAL DESA BELANTIH, KECAMATAN KINTAMANI,KABUPATEN BANGLI
}

\author{
Made Mika Mega Astuthi,S.P.,M.P. \\ Program Studi Agroteknologi, Fakultas Pertanian, Universitas Dwijendra \\ E-mail :made.mika19@gmail.com \\ Yohana D Atnasari, S.P \\ Program Studi Agribisnis, Fakultas Pertanian, Universitas Dwijendra \\ E-mail :echykyohana360@gmail.com
}

\begin{abstract}
Abstrak
Buah jeruk adalah buah yang paling banyak dikonsumsi dan sangat popular dimasyarakat, karena mempunyai sebaran tanam yang luas dan mempunyai tingkatan yang tinggi. Hal ini karena buah jeruk memiliki cita rasa, aroma, kesegaran dan sumber vitamin bagi tubuh, sehingga buah jeruk sangat digemari dan menjadi buah favorit keluarga. Tujuan penelitian ini adalah untuk mengetahui persepsi masyarakat terhadap pembelian buah jeruk lokal. Daerah penelitian diambil secara sengaja (purposive) yaitu Desa Belantih, Kecamatan Kintamani, Kabupaten Bangli. Data yang dikumpulkan adalah data primer dan sekunder dengan menggunakan teknik wawancara, observasi dan dokumentasi. Data dianalisis dengan menggunakan metode deskriptif. Hasil penelitian terhadap 40 orang konsumen diperoleh informasi bahwa pencapaian skor persepsi kategori sangat baik sebesar 30\%, Baik sebesar 55\%, dan yang menjawab sedang sebanyak $15 \%$. Ini berarti persepsi konsumen terhadap buah jeruk lokal berada pada kategori baik. Indikator yang diukur pada persepsi ini adalah pemahaman masyarakat terhadap pembelian buah jeruk lokal dan indikator terakhir mengenai persepsi masyarakat sehubungan dengan masalah budaya termasuk dikategorikan cukup baik karena masyarakat tersebut tidak bertentangan dengan nilai budaya setempat, bahkan menurut mereka persepsi masyarakat pada pembelian buah jeruk akan memberikan dukungan dalam kesehatan.
\end{abstract}

Kata Kunci : Persepsi, masyarakat, jeruk.

\begin{abstract}
Citrus fruit is the fruit most consumed and very popular in the community, because it has a wide distribution and has a high level. This is because citrus fruits have taste, aroma, freshness and a source of vitamins for the body, so that citrus fruits are very popular and become family favorite fruits. The purpose of this study was to determine people's perceptions of purchasing local citrus fruits. The research area was taken purposively, namely Belantih Village, Kintamani District, Bangli Regency. The data collected are primary and secondary data using interview, observation and documentation techniques. Data were analyzed using descriptive methods. The results of research on 40 consumers obtained information that the achievement of the perception score category was very good by $30 \%$, good by $55 \%$, and those who answered moderate were $15 \%$. This means that consumer perceptions of local citrus fruits are in the good category. The indicators measured for this perception are people's understanding of the purchase of local citrus fruits and the last indicator regarding community perceptions with regard to cultural issues is categorized as quite good because the community does not conflict with local cultural values, even according to them people's perceptions of purchasing citrus fruits will provide support in health.
\end{abstract}

Keywords: Perception, society, orange.

\section{PENDAhuluan}

Sektor pertanian merupakan sektor penting yang masih sangat diperlukan kelestariannya. Sebagian besar masyarakat Indonesia berpenghasilan dari bidang pertanian sehingga bukan saja untuk kebutuhan pangan namun juga sebagai sumber pendapatan (Sedana and Astawa, 2019; Sedana and Rahmat, 2020;. Soekartawi (2005) mengemukakan bahwa pembangunan pertanian diarahkan untuk meningkatkan produksi pertanian guna memenuhi kebutuhan pangan dan kebutuhan industri dalam negeri, meningkatkan ekspor, meningkatkan pendapatan petani, memperluas kesempatan kerja dan mendorong pemerataan kesempatan berusaha. Sektor pertanian terdiri dari beberapa subsektor yaitu subsektor 
pangan, perkebunan dan peternakan. Tantangan yang dihadapi sektor pertanian sekarang ini adalah mengenai produktivitas yang seharusnya meningkat, mengingat jumlah penduduk yang bertambah setiap tahunnya, akan tetapi di satu sisi lahan garapan sawah semakin kecil atau berkurang akibat dari peralihan lahan pertanian ke industri-industri dan perumahan (Dananjaya, 2018).

Handayani (2009) mengemukakan bahwa subsektor hortikultura memiliki potensi yang sangat besar untuk dikembangkan sebagai upaya penumbuhan perekonomian daerah maupun nasional, karena mempunyai pengaruh terhadap perbaikan gizi, pendapatan dan kesejateraan petani. Tanaman hortikultura meliputi tanaman buah-buahan, sayur - sayuran dan bunga-bungaan. Buah-buahan merupakan salah satu jenis tanaman hortikultura tahunan, merupakan sumber vitamin dan mineral.

Buah jeruk merupakan salah satu jenis buah yang menjadi komoditas unggulan yang dikembangkan,karena mempunyai sebaran tanam yang luas dan mempunyai tingkat konsumsi yang tinggi.Hal ini karena buah jeruk memiliki cita rasa,aroma,kesegaran dan sumber vitamin bagi tubuh,sehingga buah jeruk sangat digemari dan menjadi buah favorit keluarga. Menurut Rakhmat (2005) mengungkapkan bahwa persepsi adalah pengalaman tentang objek, peristiwa, atau hubungan-hubungan yang diperoleh dengan menyimpulkan informasi dan menafsirkan pesan. Persepsi ialah memberikan makna pada stimuli indrawi (sensory stimuli). Sedangkan menurut Kimbal Young (Walgito, 1981) mengatakan, persepsi adalah sesuatu yang menunjukkan aktivitas merasakan, menginterpretasikan dan memahami objek, baik fisik maupun sosial.

Seiring dengan peningkatan jumlah penduduk dan kesejatraan masyarakat, maka jumlah ketersedian jeruk lokal sudah semakin meningkat karena masyarakat menyadari pentingnya untuk mengkonsumsi buah-buahan salah satunya buah jeruk.Propinsi Bali juga termasuk daerah penghasilan buah jeruk dan mengalami peningkatan produksi setiap tahunnya. Sehingga perlu melakukan pemberdayaan petani jeruk, dimana pemberdayaan petani adalah segala upaya untuk meningkatkan kemampuan petani untuk melaksanakan usaha tani yang lebih baik melalui pendidikan dan pelatihan, penyuluhan dan pendampingan, pengembangan sistem dan sarana pemasaran hasil pertanian (Mika, 2018; Sedana and Astawa, 2018; Koming and Sedana, 2019). Pendampingan dalam pemberdayaan masyarakat seperti kegiatan integrasi yang dilaksanakan oleh Pemerintah ini berorientasi pada usaha pertanian tanpa limbah (zero waste) dan menghasilkan kebutuhan pangan manusia (food), pakan ternak (feed), pupuk (fertilizer), dan bahan bakar (fuel) yang biasa disebut 4F. Biogas yang digunakan di masing-masing lokasi Simantri menggunakan kotoran ternak sapi dan kambing (Charisma, 2019)

Sehingga perlu untuk dilakukannya penelitian mengenai persepsi masyarakat terhadap buah jeruk lokal doi Desa Belantih, Kecamatan Kintamani, Kabupaten Bangli.

\section{METODE}

Penelitian ini dilakukan di Desa Belantih, Kecamatan Kintamani, Kabupaten Bangli. Penentuan lokasi dilakukan secara sengaja (purposive sampling). Populasi dalam penelitian ini adalah semua petani jeruk yang berjumlah 40 orang. Penentuan sampel menggunakan metode sensus dimana semua populasi digunakan sebagai sampel yang berjumlah 40 orang. 
Jenis data yang digunakan dalam penelitian ini adalah data kualitatif dan data kuantitatif dengan sumber data primer dan data sekunder. Data yang dikumpulkan adalah data primer dan sekunder dengan menggunakan teknik wawancara, observasi dan dokumentasi. Data dianalisis dengan menggunakan metode deskriptif. Dalam pengukuran persepsi petani terhadap buah jeruk lokal, digunakan 15 buah pertanyaan.untuk masing-masing jawaban dari responden akan diberikan skor tertinggi untuk jawaban sangat diharapkan, oleh karena itu,kemungkinan skor yang dicapai adalah berkisar antara 15 sampai 75 . Selanjutnya total skor yang diperoleh dari seluruh pertanyaan dicari nilai persentasenya dari skor maksimal. Berdasarkan nilai pencapaian skor tersebut dan kategori skornya, persepsi petani terhadap buah jeruk lokal dikelompokkan menjadi lima kategori yaitu dari persepsi sangat baik sampai dengan persepsi yang sangat tidak baik. Secara lebih rinci dapat dijelaskan pada tabel berikut:

Tabel 1. Kategori Skor Persepsi Responden

\begin{tabular}{|c|c|c|}
\hline No. & Kategori & Persentase (\%) \\
\hline 1. & Sangat tinggi & $>84-100$ \\
\hline 2. & Tinggi & $>68-84$ \\
\hline 3. & Sedang & $>52-68$ \\
\hline 4. & Rendah & $>36-52$ \\
\hline 5. & Sangat rendah & $>20-36$ \\
\hline
\end{tabular}

\section{HASIL DAN PEMBAHASAN}

Berdasarkan data monografi Desa Belantih Tahun 2019, memiliki 2.515 kepala keluarga dengan jumlah penduduk sebanyak 5.120 orang terdiri dari laki-laki sebanyak 2,537 jiwa dan perempuan sebanyak 2.583 jiwa. Tingkat pendidikan merupakan salah satu faktor yang mempengaruhi daya fikir seseorang dlam menyerap inovasi dan informasi.pada bidang pendidikan penduduk desa Belantih yang pernah menempuh ilmu pendidikan baik dari tingkat TK sampai perguruan tinggi dapat dibedakan menjadi beberapa tingkatan pendidikan. Diketahui bahwa menurut tingkat pendidikan, penduduk di Desa Belantih tergolong baik. Hal ini dapaat dilihat bahwa tingkat pendidikan terbanyak adalah tamat SD sebanyak 2339 Orang $(23,39 \%)$, tamat SMP sebanyak 577 orang $(11,26 \%)$, tamat SMA sebanyak 1.081 orang $(21,11 \%)$

Berdasarkan mata pencaharian, penduduk Desa Belantih terbagi menjadi beberapa sector perekonomian yang terdiri dari, buruh tani, pegawai, swasta, PNS, wiraswasta atau pedagang, dan jasa Diketahui bahwa bekerja di sektor pertanian sebanyak 339 orang $(6,62 \%)$ sektor wiraswasta sebanyak 1314 orang $(25,66 \%)$, peternak 377 orang $(7,36 \%)$, buruh tani $1081(21,11 \%)$. Deskripsi responden menurut umur menguraikan atau memberikan gambaran mengenai usia produktif responden memiliki kemampuan untuk melakukan aktivitas yang rutin yang menjadi sampel dalam penelitian ini. Sebagian besar petani memiliki umur yang berada pada kategori usia produktif (15-64 tahun) yaitu 25 Orang $(62,5 \%)$ dan sisanya 15 orang $(37,5 \%)$ termasuk kategori tidak produktif $(>64)$.

Jenis kelamin responden dalam penelitian ini dapat dikelompokan dalam dua kelompok yaitu kelompok laki-laki dan wanita. Jenis kelamin responden dari 40 orang responden yang menjadi sampel dalam penelitian ini adalah laki-laki yakni 25 orang atau $62,5 \%$ dan perempuan sebanyak 15 orang 
37,5\%. Berdasarkan pada tingkat pendidikan formalnya, sebagian besar Anggota kelompok tani jeruk telah menamatkan pendidikan pada tingkat SD sebanyak 20 (50\%) sedangkan yang tamat SMP sebanyak 10 orang $(25 \%)$ dan tamat SMA sebanyak 10 orang $(25 \%)$. Karakteristik responden menurut jenis kelamin Responden,maka dari 40 responden yang menjadi sampel dalam penelitian ini maka kelompok responden berdasarkan jenis kelamin yang terbesar dalam penelitian ini adalah tamat SD 16 orang $(40 \%)$,tamat SMA 12 orang (30\%) tamat SMP 8 orang (20\%) dan perguruan tinggi 4 orang $(10 \%)$ hal ini menunjukan bahwa tingkat pendidikan petani di kelompok tergolong relatif baik karena sebagian besar mereka telah menamatkan pendidikan formalnya di tingkat SMA dan bahkan ada juga tamat perguruan tinggi.

Hasil penelitian terhadap 40 orang konsumen diperoleh informasi bahwa pencapaian skor persepsi kategori sangat baik sebesar 30\%, Baik sebesar 55\%, dan yang menjawab sedang sebanyak $15 \%$. Ini berarti persepsi konsumen terhadap buah jeruk lokal berada pada kategori baik. Secara lebih rinci, distribusi frekuensi konsumen didasarkan pada persepsinya dapat dilihat pada tabel berikut.

Tabel 2. Distribusi frekuensi konsumen didasarkan pada persepsinya

\begin{tabular}{|c|l|c|c|}
\hline No. & Kategori & $\begin{array}{l}\text { Frekuensi } \\
\text { (Orang) }\end{array}$ & $\begin{array}{l}\text { Prosentase } \\
(\boldsymbol{\%})\end{array}$ \\
\hline 1. & Sangat baik & 12 & 30,00 \\
\hline 2. & Baik & 22 & 55,00 \\
\hline 3. & Sedang & 6 & 15.00 \\
\hline 4. & Tidak baik & 0 & 0,00 \\
\hline 5. & Sangat tidak baik & 0 & 0,00 \\
\hline & Jumlah & 40 & 100 \\
\hline
\end{tabular}

Sumber : Olahan Data Primer

Memperhatikan data pada Tabel 2, terlihat bahwa sebagian besar konsumen (55\%) memiliki persepsi yang baik, dan tidak ada petani yang memiliki persepsi yang tidak baik dan bahkan sangat tidak baik. Ini berarti bahwa konsumen memiliki pemahaman dan ketertarikan terhadap jeruk lokal untuk dikonsumsi. Indikator yang digunakan untuk mengetahui dan mengukur persepsi masyarakat terhadap pembelian buah jeruk lokal di bali, yaitu:

\section{Rasa buah jeruk}

Rasa buah jeruk lokal yang disukai masyarakat di Desa Belantih Kecamatan Kintamani Kabupaten Bangli adalah rasa manis sedikit asam kandungan asam sitrat mengindikasikan adanya Vitamin $\mathrm{C}$ yang cukup tinggi pada jeruk menyebabkan buah jeruk lokal cendrung memiliki rasa yang asam.Tingginya kandungan air dalam jeruk memberikan sensasi yang segar saat dikonsumsi.Ini merupakan salah satu ciri khas buah tropis yang banyak digemari oleh konsumen begitu jga di Desa Belantih Kecamatan Kintamani Kabupaten Bangli.

\section{Warna Buah jeruk}

Warna buah jeruk lokal yang disukai masyarakat di Desa Belantih Kecamatan Kintamani Kabupaten Bangli adalah warna buah kuning kehijauan.Buah jeruk lokal memiliki kulit buah yang hijau pada waktu masih muda dan mulai menguning ketika mulai masak.perubahan warna pada buah merupakan suatu perubahan yang jelas nampak oleh masyarakat. 
Perubahan tersebut digunakan sebagai indikator sudah masak atau belum.perubahan yang umum terjadi adalah hilangnya warna hijau.Buah buahan non klimakterik seperti jeruk juga menunjukan tandatanda kehilangan warna hijau dengan dicapainya kualitas konsumsi (Bambang, 2008). Buah jeruk lokal berwarna kuning kehijauan oleh masyarakat dianggap sudah matang sehingga rasa buah jeruk yang dikonsumsi tidak terlalu asamdan layak untuk dikonsumsi.

\section{Ukuran Buah Jeruk}

Ukuran buah berkaitan dengan jumlah buah tiap kilogramnya. Ukuran buah yang paling banyak dipilih masyarakat buah jeruk lokal adalah buah jeruk yang berukuran sedang yaitu 8 sampai 9 buah perkilogram. Sebagian besar masyarakat melakukan pembelian buah jeruk dengan jumlah pembelian 1 hingga 2 kilogram dengan isi setiap kilogramnya 8 hingga 9 buah sudah cukup untuk memenuhi kebutuhan keluarga jumlah anggota keluarga responden yang sebagian besar beranggota 4-5 orang sudah dapat terpenuhi kebutuhannnya dalam sekali pembelian buah jeruk dengan ukuran tersebut.

\section{Aroma Buah Jeruk}

Aroma buah jeruk lokal yang disukai masayrakat di Desa Belantih Kecamatan Kintamani Kabupaten Bangli adalah aroma segar. Aroma memaikan peranan penting dalam perkembangan kualitas pada bagian buah yang dapat dikonsumsi.Aroma terjadi karena adanya sistensis senyawa organik yang bersifat mudah menguap selama fase pemasakan. Senyawa volatile ini sangat penting bagi konsumen untuk menilai tingkat kematangan dan kemasakan buah (Bambang, 2008). Aroma buah jeruk yang khas berasal dari kulit buah yang mengandung banyak minyak atsiri. Semakin banyak kandungan minyak atsirinya maka aroma semakin kuat, aroma segar yang keluar dari buah jeruk juga menandakan buah tersebut masih segar, tidak layu karena proses penyimpanan yang terlalu lama. Kandungan air juga masih banyak sehingga diharapkan rasa yang diberikan sudah sesuai yang dinginkan masyarakat.

\section{PENUTUP}

\section{Simpulan}

Hasil penelitian terhadap 40 orang konsumen di Desa Belantih,Kecamatan Kintamani, Kabupaten Bangli diperoleh informasi bahwa pencapaian skor persepsi kategori sangat baik sebesar 30\%, Baik sebesar 55\%, dan yang menjawab sedang sebanyak 15\%. Ini berarti persepsi konsumen terhadap buah jeruk lokal berada pada kategori baik. Ini berarti bahwa konsumen memiliki pemahaman dan ketertarikan terhadap jeruk lokal untuk dikonsumsi. Indikator yang digunakan untuk mengetahui dan mengukur persepsi masyarakat terhadap pembelian buah jeruk lokal di bali, yaitu rasa buah jeruk, warna buah, ukuran buah, dan aroma buah jeruk.

\section{Saran}

Agar kedepannya nanti, petani lebih bisa meningkatkan produksi dan kualitas buah jeruk lokal.Sehingga kedepannya buah jeruk lokal bisa eksis dan di cintai. Masyarakat juga, agar tetap selalu mengkonsumsi buah-buahan lokal, khusunya jeruk yang kaya akan vitamin .

\section{DAFTAR PUSTAKA}

Astuthi,M.M. M..2018. Pemberdayaan Petani Melalui Program Simantri Di Kelompok Tani Tunjung Mekar. dwijenAGRO. Vol. 8 No. 2 
Bambang Cahyono. (2008). Tomat Usaha Tani dan Penanganan Pascapanen.Yogyakarta:Kanisius.

Dananjaya, I.G.A.N. 2018. Peran Pendamping Simantri untuk Meningkatkan Kesejahteraan Petani di Kabupaten Tabanan. Jurnal dwijenAGRO, Vol. 8. No.2.

Dewi, K. A. C. J..2019. Pemanfaatan Biogas Untuk Mengurangi Pengeluaran Gas Lpj Di Kelompok Tani Ternak Swaka Mitra (Studi Kasus di Desa Dencarik, Kecamatan Banjar, Kabupaten Buleleng, Bali). dwijenAGRO. Vol. 9 No. 1

Handayani. 2009. Prospek pengembangan tanaman jeruk siam (Citrus nobilis) berwawasan agribisnis di kecamatan bolano lambunu kabupaten parigi moutong J. Agrolan.

Rakhmat (2005). Rakhmat, Jalaludin. 2005. Psikologi Komunikasi. Bandung: PT. Remaja Rosdakarya.

Sedana, G. and I N.D. Astawa. 2018. Institutional Adjustment of Subak (Traditional Irrigation System) Orienting Business: Case of Cooperative of Subak Guama, Bali Province, Indonesia International Journal of Current Research Vol. 10, Issue 06:70418-70423.

G Sedana, I N.D Astawa. 2019. Establishment of Inclusive Business on Coffee Production in Bali province: Lesson from the Coffee Development Project in Nusa Tenggara Timur Province, Indonesia.

Asian Journal of Agriculture and rural Development Vol. 9, Issue 1:111-122.

Sedana, G. and A. Rahmat. (2020). Alternative Policies to Strengthen the Traditional Irrigation System for Supporting the Food Security Program: Case of The Subaks' System in Bali, Indonesia. International Journal of Advanced Science And Technology, Vol. 29, No. 7s: 973-984

Soekartawi. 2005. Agribisnis Teori dan Aplikasinya. PT. Raja Grafindo Persada. Jakarta

Walgito, Bimo.1981.Pengantar Psikologi Umum.Yogyakarta: Penerbit ANDI. 